Received: 27.12 .2018

Revised: 04.03.2019

Accepted: 22.03 .2019

DOI: $10.17804 / 2410-9908.2019 .2 .016-027$

\title{
A METHOD FOR EXPERIMENTAL INVESTIGATION OF DEGRADATION PROCESSES IN MATERIALS
}

\author{
V. I. Mironov ${ }^{1, \text { a)* }}$, I. G. Emelyanov ${ }^{1, \text { b) }}$, D. I. Vichuzhanin ${ }^{1, ~ c)}$, I. S. Kamantsev ${ }^{1, \text { d) }}$, \\ V. V. Yakovlev ${ }^{2, \text { e) }}$, D. A. Ogorelkov ${ }^{1,2, f)}$, and L. M. Zamaraev ${ }^{1, g)}$ \\ ${ }^{I}$ Institute of Engineering Science, Ural Branch of the Russian Academy of Sciences, \\ 34 Komsomolskaya St., Ekaterinburg, 620149, Russian Federation \\ ${ }^{2}$ B. N. Yeltsin Ural Federal University, 19 Mira St, Ekaterinburg, 620002, Russian Federation
}

a) (iD https://orcid.org/0000-0002-5150-6074 Mironov.vi@mail.ru;

b) iD https://orcid.org/0000-0002-9733-5485 emelyanov@imach.uran.ru;

c) (iD https://orcid.org/0000-0002-6508-6859 mmm @imach.uran.ru;

d) (iD https://orcid.org/0000-0003-0775-4043 trophyland@ mail.ru;

e) iD https://orcid.org/0000-0002-5759-8483 yoshkassa@mail.ru;

f) (iD https://orcid.org/0000-0002-7412-3316 ogorelkov.dimon@yandex.ru;

g) iD https://orcid.org/0000-0003-4617-0825 leva.zam@mail.ru

\author{
*Corresponding author. E-mail: visim.vm@mail.ru \\ Address for correspondence: ul. Komsomolskaya, 34, 620049, Ekaterinburg, Russian Federation
} Tel.: +79221558983

In most cases, long-term degradation processes in the materials of metal structures are the main cause of their catastrophic destruction. A method for the experimental construction of rheological dependences is proposed to describe the kinetics of these processes. The phenomenological representation of the degradation process as the transition of a ductile material to a brittle state is based on simple testing of single samples of a material in a rigid loading device. It is shown that such external factors as cyclic loading and hydrogenation change the parameters of the resulting static diagram, first of all, the available plasticity determined by the length of the diagram. It is noted that tests with the construction of complete diagrams with a falling branch offer a unified methodological basis for the investigation of degradation processes in steels and alloys.

Keywords: degradation, complete deformation diagram, cyclic loading, hydrogenation, single samples, softening, kinetic curves, rigid loading device.

\section{Acknowledgment}

The work was performed within the state assignment, theme No. 0391-2016-0001.

\section{References}

1. Pronikov A.S. Nadeznost mashin [Reliability of Machines]. Moscow, Mashinostroienie Publ., 1978, 592 p. (In Russian).

2. Bolotin V.V. Resurs mashin i konstruktsiy [Resource of Machines and Structures]. Moscow, Mashinostroienie Publ., 1990, 448 p. (In Russian).

3. Veselov I., Emelyanov I., Fedotov V. Research of the Tension of the Shell Working in Hydrogen-Containing Environment. In: Proceedings of the 13th World Hydrogen Energy Conference, Beijing, China, June 12-15, 2000, pp. 1041-1045.

4. Cherdantsev Y., Chernov I., Tyurin Y. Research Methods of Metal-Hydrogen Systems: Textbook. Tomsk, TPU Publ., 2008. (In Russian). 
5. Rakhmatulin Kh.A., Demyanov Yu.A. Prochnost pri intensivnykh kratkovremennykh nagruzkakh [Strength under Intensive Momentary Loads]. Moscow, Fizmatgiz Publ., 1961, 393 p. (In Russian).

6. Koneva N.A., Sosnin O.V., Teplyakova L.A., B.E. Громов, B.В. Коваленко. Evolyutsiya dislokatsionnykh substruktur pri ustalosty [Evolution of Dislocation Substructures under Fatigue]. Novokuznetsk, 2001. (In Russian).

7. Terent'ev V.F., Kolmakov A.G., Kurganova Y.A. Teoriya i praktika povysheniya nadezhnosti i rabotosposobnosti konstruktsionnykh metallicheskikh materialov: uchebnoe posobie [Theory and Practice of Improving the Reliability and Performance of Structural Metallic Materials: Tutorial]. Ulyanovsk, UlGTU Publ., 2010, 268 p. ISBN 978-5-9795-0680-7. (In Russian).

8. Volkov S.D., Gus'kov Yu. P., Krivospitskaya V.I., Mironov V.I., Sokovnin Y.P., Sokolov P.S. Experimental functions of the resistance of alloy steel in tension and torsion. Strength of Materials, 1979, vol. 11, iss. 1, pp. 1-5. DOI: 10.1007/BF00806220.

9. Volkov S.D. Funktsiya soprotivleniya materialov i postanovka kraevykh zadach mekhaniki razrusheniya [Function of the Strength of Materials and the Formulation of Boundary Value Problems in Fracture Mechanics]. Sverdlovsk, UNTs AN SSSR Publ., In-t metallurgii, 1968, 65 p. (In Russian).

10. Volkov S.D. The problem of strength and fracture mechanics. Problemy Prochnosti, 1978, no. 7, pp. 3-10. (In Russian).

11. Struzhanov V.V., Mironov V.I. Deformatsionnoe razuprochnenie materiala v elementakh konstruktciy [Work Softening of Structure Elements Materials]. Ekaterinburg, Izd-vo UrO RAN Publ., 1995. (In Russian).

12. Mironov V.I., Lukashuk O.A. Influence of material structural inhomogeneity on fracture strength of constructional elements. J. Key Engineering Materials, 2017, vol. 735, pp. 89-94. DOI: $10.4028 /$ www.scientific.net/KEM.735.89.

13. Mironov V.I., Andronov V.A., Jakushev A.V., Bambulevich V.B. Method and device for tension testing. RF Patent 2251 676, 2005. (In Russian).

14. Vildeman V.E., Tretyakov M.P., Tretyakova T.V. et al. Eksperimental'nye issledovaniya svoystv materialov pri slozhnykh termomekhanicheskikh vozdeystviyakh [Experimental Investigation of Material Properties under Complex Thermomechanical Loading, ed. by V. E. Wildeman]. Moscow, Fizmatlit Publ., 2012. (In Russian).

15. Lebedev A.A., Chausov N. G. Phenomenological fundamentals of the evaluation of crack resistance of materials on the basis of parameters of falling portions of strain diagrams. Strength of Materials, 1983, vol. 15, iss. 2, pp. 155-160. DOI: 10.1007/BF01523460.

16. Goldenblat I.I, Bazhenov, V.L., Kopnov V.A. Dlitelnaya prochost v mashinostroenii [LongTerm Strength in Machine Construction]. Moscow, Mashinostroenie Publ., 1977. (In Russian).

17. Rabotnov Yu.N. Polzuchest elementov konstruktsiy [Creep of Construction Elements]. Moscow, Nauka Publ., 1955. (In Russian).

18. Karpenko G.V., Kripyakevich R.I. Vliyanie vodoroda na svoystva stali [The Effect of Hydrogen on Steel Properties]. Moscow, Mettallurgizdat Publ., 1962. (In Russian).

19. Terent'ev V.F. Ustalostnaya procnost' metallov $i$ splavov [Fatigue Strength of Metals and Alloys]. Moscow, Intermet Inzhiniring Publ., 2002. (In Russian).

20. Ustalost $i$ vynoslivost metallov [Fatigue and Endurance of Metals, ed. by G. V. Uzhik]. Moscow, Izd-vo. inostr. lit. Publ., 1963. (In Russian).

21. Emelyanov I.G. Mironov V.I. Dolgovechnost' obolochennykh konstruktsiy [Durability of Shell Structures]. Ekaterinburg, RIO UrO RAN Publ., 2012. ISBN 978-5-7691-2322-1. (In Russian).

22. Ovchinnikov I.I., Ovchinnikov I.G. Influence of hydrogen-containing media at high temperatures and pressures on the behavior of metals and structures made of metals. Naukovedenie, 2012, 
no. 4. Available at: https://naukovedenie.ru/PDF/60tvn412.pdf (accessed at 20.09.2017). (In Russian).

23. Pisarev A.A., Tsvetkov I.V., Yarko E.D. Pronitsaemost vodoroda cherez metally [Hydrogen Permeability through Metals: Tutorial]. Moscow, MIFI Publ., 2008. (In Russian).

24. Mironov V.I., Emelyanov I.G., Yakushev A.V., Lukashuk O.A. Development of rapid method for car steel quality control. Transport of the Ural, 2012, no. 2 (33), pp. 13-18. (In Russian).

25. Lebedev A.A., Chausov N.G. Novye metody otsenki degradatsii mekhanicheskikh svoystv metalla konstruktsiy $v$ protsesse narabotki [New Methods of Estimating the Degradation of Mechanical Properties of Structural Steel in Operation, the Monography]. Kiev, IPP NANU Publ., 2004. 
Подана в журнал: 27.12.2018

УДК 620.172 .25

DOI: $10.17804 / 2410-9908.2019 .2 .016-027$

\section{СПОСОБ ЭКСПЕРИМЕНТАЛЬНОГО ИССЛЕДОВАНИЯ ДЕГРАДАЦИОННЫХ ПРОЦЕССОВ В МАТЕРИАЛЕ}

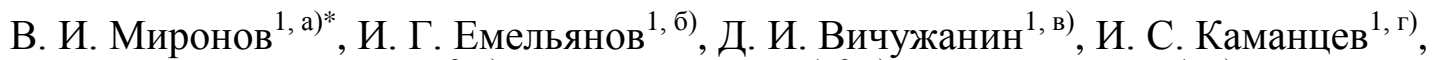
В. В. Яковлев ${ }^{2, \text { д) }}$, Д. А. Огорелков ${ }^{1,2, \text { e)}, ~ Л . ~ М . ~ З а м а р а е в ~}{ }^{1, ж)}$

${ }^{1}$ Федеральное государственное бюджетное учреждение науки Институт матиноведения Уральского отделения Российской академии наук, ул. Комсомольская, 34, Екатеринбург, Российская Федерация

${ }^{2}$ Уральский Федеральный Университет, Мира, 19, Екатеринбург, Российская Федераичи

a) (iD https://orcid.org/0000-0002-5150-6074 @ Mironov.vi@mail.ru;

б) (iD https://orcid.org/0000-0002-9733-5485 @ emelyanov@imach.uran.ru;

в) (D) https://orcid.org/0000-0002-6508-6859 mmm@imach.uran.ru;

r) (iD https://orcid.org/0000-0003-0775-4043 잔 trophyland @ mail.ru;

य) (iD https://orcid.org/0000-0002-5759-8483 @ yoshkassa@mail.ru;

e) (iD https://orcid.org/0000-0002-7412-3316 @ ogorelkov.dimon@yandex.ru;

ж) (D) https://orcid.org/0000-0003-4617-0825 @ leva.zam@mail.ru

* Ответственный автор. Электронная почта: visim.vm@mail.ru

Адрес для переписки: ул. Комсомольская, 34, 620040, Екатеринбург, Российская Федерация Тел.: +7-922-155-89-83

Длительные деградационные процессы в материале эксплуатируемых металлических конструкций в большинстве случаев являются основной причиной их катастрофического разрушения. Предложен способ экспериментального построения реологических зависимостей для описания кинетики подобных процессов. Феноменологическое представление деградационного процесса как перехода пластичного материала в хрупкое состояние основано на простых испытаниях однократных образцов материала в жестком нагружающем устройстве. Показано, что такие внешние факторы, как циклическое нагружение и наводороживание, меняют параметры получаемой статической диаграммы, прежде всего, располагаемой пластичности, определяемой длиной диаграммы. Отмечается, что испытания с построением полных диаграмм с падающей ветвью дают единую методологическую базу для исследования деградационных процессов в сталях и сплавах.

Ключевые слова: деградация, полная диаграмма деформирования, циклическое нагружение, наводороживание, однократные образцы, разупрочнение, кинетические кривые, жесткое нагружающее устройство.

\section{1. Введение}

С точки зрения физической надежности машин корректная оценка их ресурса должна базироваться на исследовании деградационных процессов в материале элементов конструкции в эксплуатации $[1,2]$. Переменные силовые и температурные поля, агрессивные среды, радиация и другие эксплуатационные воздействия снижают предельные показатели прочности и пластичности материала. Металлические конструкции, широко применяемые в машиностроении, космонавтике, энергетике и других отраслях техники, зачастую испытывают одновременное воздействие нескольких негативных факторов. В этом случае оценка ресурса сводится к численному решению достаточно сложных связанных физико-механических и диффузионно-механических задач $[3,4]$. Модель материала в подобных задачах содержит 
реологические уравнения, описывающие кинетику деградационных процессов, протекающих на структурном уровне.

Механизмы, условия протекания и характерные времена деградационных процессов в конструкционных материалах весьма разнообразны. Объединяющим признаком может служить зависимость их интенсивности от уровня механических напряжений, точнее от напряженного состояния элемента конструкции. Например, физический механизм влияния напряженного состояния на диффузию примеси в металле заключается в следующем. При растягивающих напряжениях соответствующим зонам энергетически выгодно притягивать атомы примеси (восстановление равновесия), а при сжимающих напряжениях - выталкивать. Пропорциональны амплитуде напряжений и гистерезисные потери энергии, затрачиваемой на необратимые изменения в материале при циклическом нагружении.

Определим деградационный процесс, как переход пластичного материала в хрупкое состояние, причем независимо от того, протекает ли он локально, на поверхности или в значительном объеме элемента конструкции. Такое определение представляется достаточно общим, позволяющим описать широкий круг явлений с единых позиций. Например, при исследовании влияние различных факторов на дислокационный механизм пластической деформации. Известно, что при достаточно большой скорости активного нагружения не успевают срабатывать источники дислокаций [5] и разрушение выглядит хрупким. Блокировка или активация движения дислокаций при изменении температуры определяют изменение свойств материала в процессе теплопередачи, т. е. в процессе средней скорости. В медленных процессах (диффузия примесей, старение, усталость) формируются критические дислокационные структуры, предшествующие разрушению материала $[6,7]$.

Предлагается использовать для феноменологического описания деградационных процессов разной природы эксперимент с построением полных диаграмм деформирования (ПДД). Полная диаграмма с падающей до нуля ветвью, интегрально описывающей стадию разупрочнения материала, дает наиболее полное и логически завершенное представление о его сопротивлении деформированию [7, 8]. Идея использования ПДД для построения физических уравнений неоднородных материалов принадлежит профессору С. Д. Волкову $[9,10]$. Суть ее в том, что прежде чем изучать разрушение, как новое явление в поведении конструкций под нагрузкой, следует выделить новое свойство материала, а именно, стадию разупрочнения. В статье рассматрена принципиальная возможность описания кинетики деградационных процессов в материале по изменению параметров ПДД под воздействием эксплуатационных факторов: циклического нагружения, агрессивной среды, температуры и др.

\section{2. Материал и средства эксперимента с построением ПДД}

Падающая ветвь на диаграмме деформирования может быть построена при испытании малых образцов любого структурно неоднородного материала при наличии достаточно жесткого нагружающего устройства.

\section{1. Полная диаграмма деформирования}

Наглядное представление о стадии разупрочнения на диаграмме статического растяжения и деградации параметров ПДД дает численный эксперимент с использованием дискретных моделей материала и аппарата теории катастроф $[11,12]$. Выявлено, что падающая ветвь на диаграмме характерна для структурно неоднородных материалов и может быть построена при испытании образца малого объема в достаточно жесткой испытательной машине. К настоящему времени преодолены технические трудности построения ПДД [13, 14], и такие диаграммы растяжения и кручения могут быть получены для конструкционных материалов разных классов (рис. 1). 


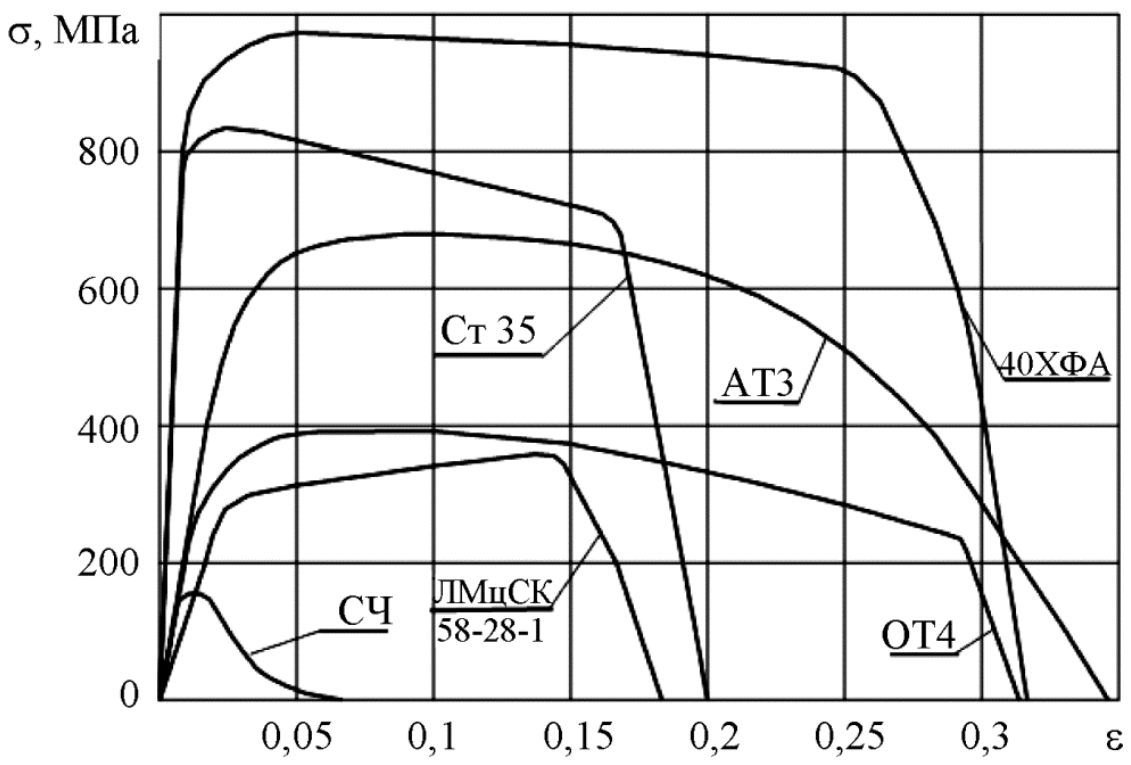

Рис. 1. Экспериментальные диаграммы сталей и сплавов по испытаниям образцов диаметром и длиной по 2 мм

Диаграммы на рис. 1 построены для малых однократных образцов в жестком нагружающем устройстве [13]. В стандартных образцах рабочая часть вне локализованной зоны разрушения переходит в систему нагружения, снижая ее жесткость, что не позволяет построить падающую ветвь ПДД. Для большинства материалов деформация разрушения значительно превосходит деформацию предела прочности. Переход на заключительный участок ПДД связан с исчерпанием диссипативных свойств материала по пластическому механизму. Соответствующая деформация определяет располагаемую пластичность материала. Тангенс угла наклона завершающего участка к отрицательному направлению оси деформаций по аналогии с модулем упругости называют модулем хрупкости. Модуль хрупкости, определяющий работу разрушения образца, тесно коррелирует с трещиностойкостью материала [15].

Таким образом, качественные модельные представления о ПДД с падающей до нуля ветвью получили экспериментальное подтверждение. В то же время испытания на растяжение и кручение образцов стали 30ХГСА показали неприемлемость гипотезы единой кривой во всем диапазоне деформирования [8]. Вопрос об инвариантной форме физических уравнений, описывающих стадию разупрочнения материала, остается открытым. По этой причине пока нельзя построить теорию деградационных процессов на уровне строгости, принятом в механике деформируемого твердого тела. Но это не мешает, на наш взгляд, дать интегральную оценку кинетики эволюционных процессов в материале образца по изменению представительных параметров ПДД. В соответствии с принятым выше определением деградационного процесса в качестве представительного параметра предлагается располагаемая пластичность. В качестве внешнего воздействия, меняющего параметры ПДД, рассмотрим циклическую тренировку образца.

\section{2. Взаимосвязь статических и циклических свойств литой стали}

Идея построения реологических уравнений деградационных процессов по изменению статической диаграммы растяжения не нова. Так строятся теории длительной прочности, ползучести, водородной хрупкости [16-18], т. е. в тех случаях, когда внешний фактор действует на весь объем образца. В соответствии с постулатом Друккера рассматривалась только восходящая ветвь статической диаграммы. Попытки построения аналогичной теории усталости оказались неудачными, установить взаимосвязь статиче- 
ских и циклических свойств материала в испытаниях тренированных стандартных образцов не удалось $[19,20]$. Причиной тому служит высокая локализация усталостных повреждений в поверхностном слое и по длине образца. Деградацию механических свойств удалось зафиксировать в испытаниях тренированных однократных образцов, которые используются для построения ПДД [21].

На первом этапе исследования свойств литых вагонных сталей испытывались малые образцы (рис. 2), выточенные из стандартных образцов стали 20ГЛ, циклически тренированных до разной степени наработки с периодическим удалением поверхностного слоя.

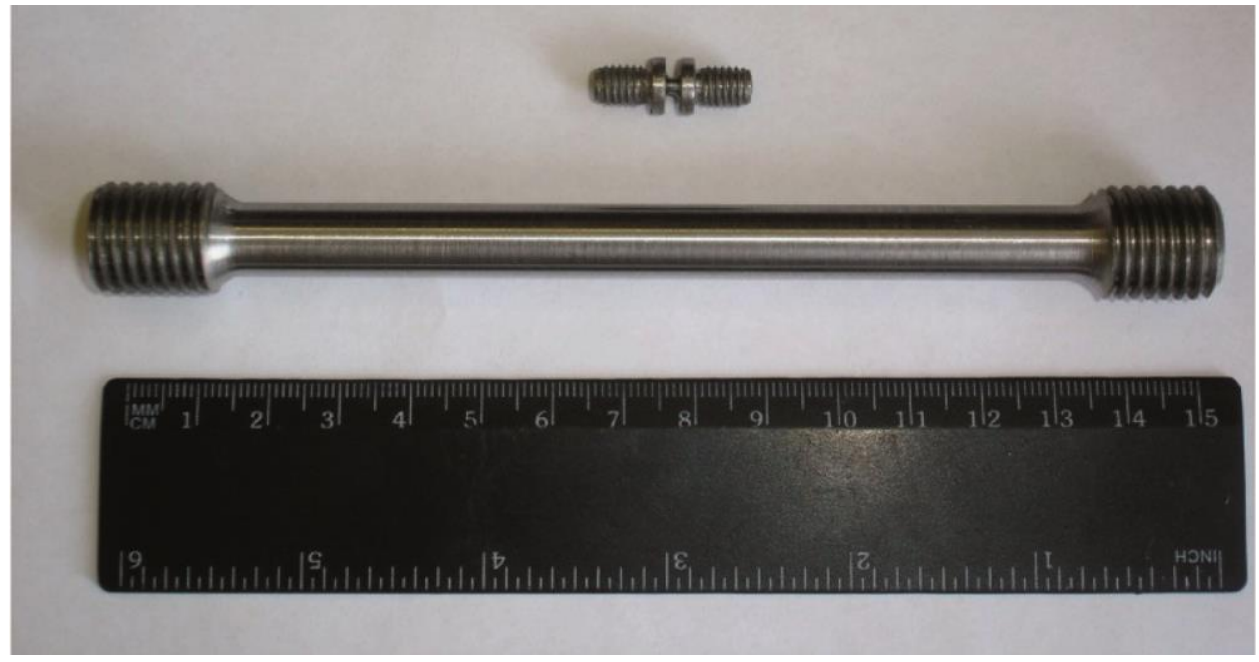

Рис. 2. Внешний вид образцов для исследования

В усталостных испытаниях трех стандартных образцов диаметром 10мм пульсирующим растяжением на уровне максимального напряжения $\sigma_{\mathrm{M}}=260$ МПа минимальная долговечность составила $N_{1}=88$ тыс. циклов. Четвертый образец тренировали до 80 тыс. циклов, обтачивали до 9 мм и на том же уровне $\sigma_{\text {м }}=260$ МПа циклически доводили до разрушения: $N_{4}=188$ циклов. Пятый образец тренировали до 80 тыс. циклов, обтачивали до 9 мм. Затем тренировали еще на 80 тыс. циклов, обтачивали до 8 мм и на уровне $\sigma_{\text {м }}=260$ МПа циклически доводили до разрушения: $N_{5}=554$ тыс. циклов.

Далее из разрушенных стандартных образцов, вытачивали по три-четыре образца диаметром и длиной по 2 мм (рис. 2) и испытывали на растяжение в жестком нагружающем устройстве с построением ПДД. Осредненные ПДД из образцов с разной наработкой практически совпали. Следовательно, основной металл образца не устает, или устает значительно медленнее, чем в поверхностном слое, где в основном накапливаются усталостные повреждения [19].

На втором этапе для исследования циклической деградации свойств литых сталей тренировали непосредственно малые образцы при постоянной амплитуде напряжения $0,8 \sigma_{0,2}$ до разной степени наработки, а затем строили ПДД (рис. 3).

Усталостные процессы приводят прежде всего к вырождению пластических свойств сталей, определяемому по уменьшению длины падающей ветви полной диаграммы деформирования. При этом рельеф поверхности излома меняется от вязкого ямочного в материале без наработки до сглаженного рельефа с мелкими неглубокими ямками и площадками квазискола и скола после наработки $n / N=0,7$. Неоднородность структуры стали 20ГЛ, обусловленная значительным количеством веерообразных скоплений неметаллических включений на основе сульфида марганца округлой морфологии, приводит к многочисленным расслоениям материала по межфазным границам сульфид-матрица, что способствует диссипации энергии разрушения на ста- 
дии развития трещины. Качественно аналогичные результаты получены при тренировке на уровне напряжений $0,6 \sigma_{0,2}$, а также в испытаниях литой стали 20 Л.
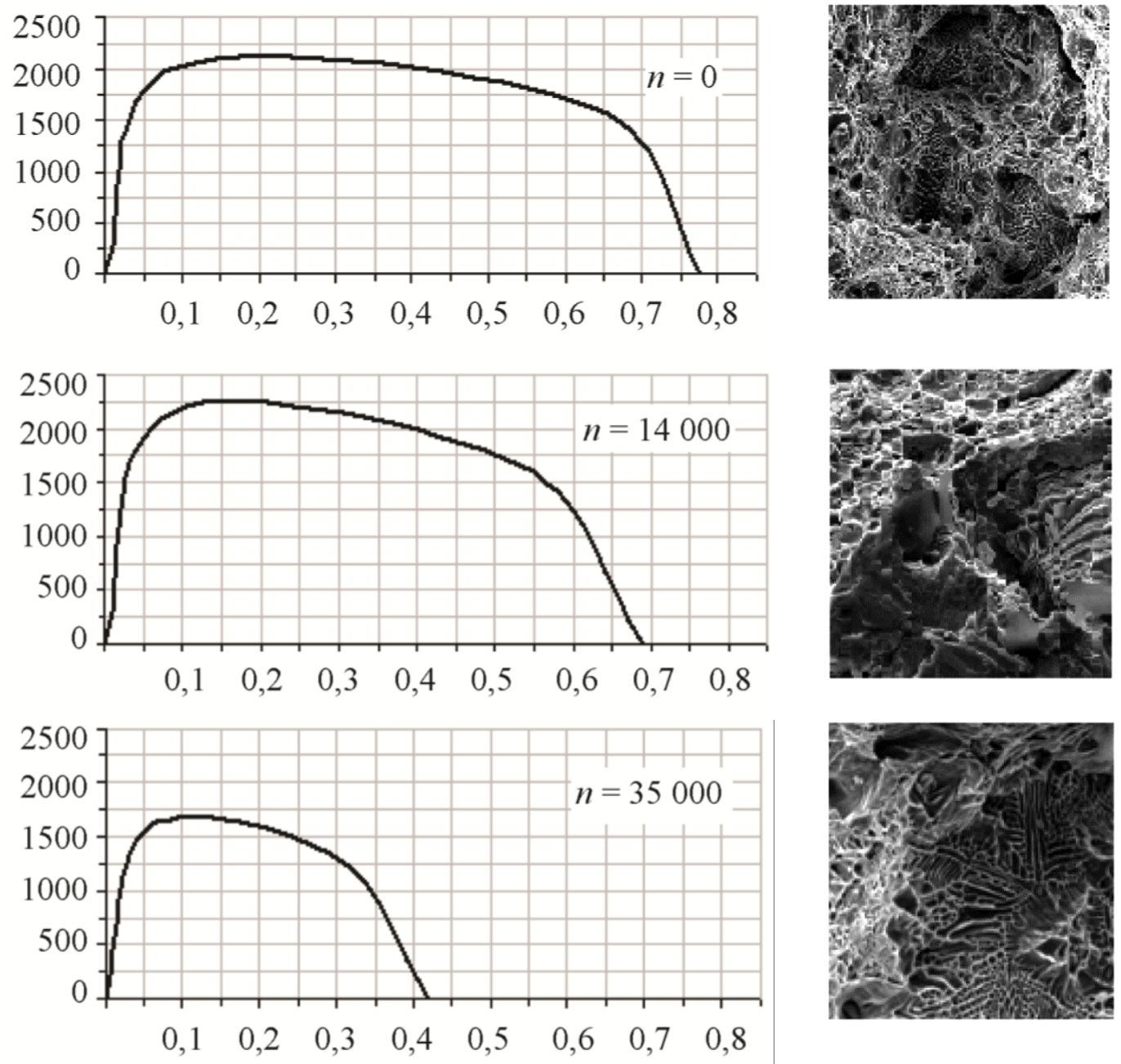

Рис. 3. Деградация ПДД стали 20ГЛ и поверхности излома после циклирования при постоянной амплитуде напряжения

Роль испытаний с построением ПДД не ограничивается исследованием циклической деградации материала. Значительное снижение располагаемой пластичности наблюдается в пробных испытаниях образцов титанового сплава ВТ20 после выдержки в водородосодержащей среде.

\section{3. Влияние наводороживания на механические свойства титанового сплава}

Пластины для наводороживания вырезались из прокатанной полосы титанового сплава толщиной 10 мм вдоль и поперек направления прокатки. Из этих пластин выточено по четыре образца диаметром и длиной по 2 мм (рис. 2). В испытаниях на растяжение малых образцов использовалось нагружающее устройство повышенной жесткости с параллельными тягами [21]. Построить диаграмму деформирования с падающей до нуля ветвью не удалось, что послужило поводом для изобретения более эффективного кольцевого устройства [13]. Тем не менее можно оценить располагаемую пластичность по осредненным условным диаграммам, приведенным на рис. 4 (кривые 1 и 2). 


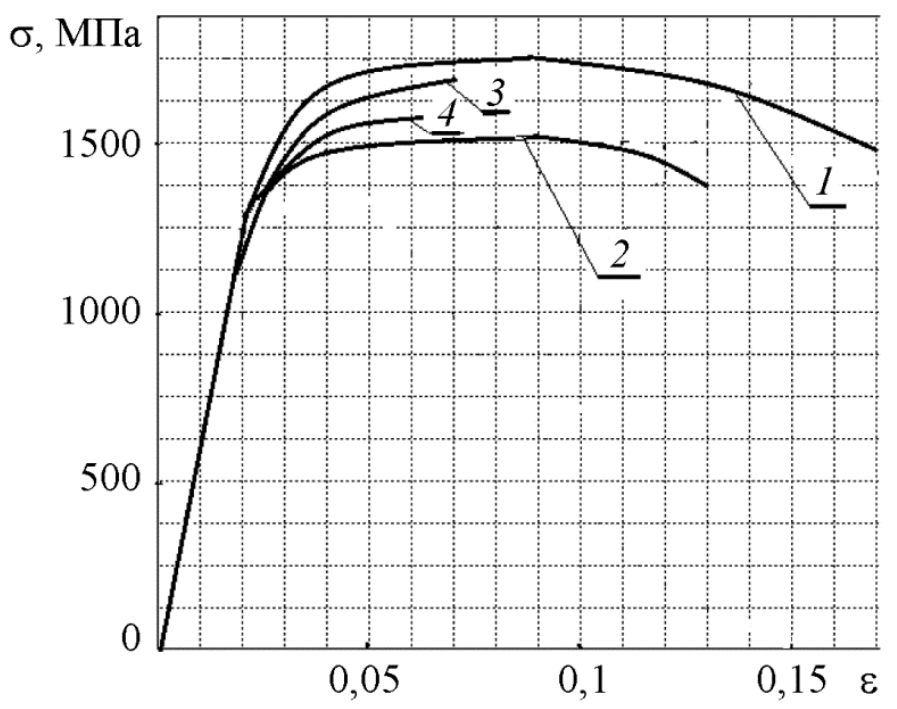

Рис. 4. Условные диаграммы деформирования сплава ВТ20

В анизотропной полосе она выше в поперечном направлении (рис. 4, диаграмма 1 ). Далее пластина, вырезанная поперек полосы, наводороживалась в реакторе с вакуумом после предварительного отжига при температуре $850^{\circ}$ в течение 30 мин. В качестве источника водорода использовался гидрид титана, который при температуре $400^{\circ}$ начинает выделять водород. При дальнейшем росте температуры наблюдался рост давления, поскольку пластина не успевала поглотить весь водород. Нагревание проводилось так, чтобы давление не превышало 1атм и длилось до равновесной концентрации водорода при температуре $850^{\circ}$. Для дальнейшего насыщения водородом термический режим наводороживания включал медленное ступенчатое (по 20 мин.) снижение температуры до $600^{\circ}$ и остывание с печью. Показания микроанализатора выявили неоднородное распределение водорода по фазам и в местах скопления дислокаций, но в целом по сечению пластины водород распределялся равномерно.

Результаты испытаний на растяжение двух малых образцов, выточенных из наводороженной пластины, приведены на рис. 4 (диаграммы 3 и 4). Наблюдается некоторое снижение прочности и значительное снижение располагаемой пластичности титанового сплава ВТ20 при данном режиме наводороживания.

\section{3. Результаты и обсуждение}

Приведенные результаты экспериментов с литыми сталями дают возможность строить одномерные модели циклической деградации материала деформационного или силового типа. Кинетические кривые деградации деформационных и прочностных свойств материала строятся по вырождению ПДД и выражаются в терминах деформаций и напряжений. Например, для стали 20ГЛ опытные данные аппроксимируются показательной функцией и в силовой постановке задачи имеют вид:

$$
\begin{aligned}
& S\left(\sigma_{\mathrm{M} 1} ; n\right)=610-350(n / 72800)^{1,9} ; \\
& S\left(\sigma_{\mathrm{M} 2} ; n\right)=610-265(n / 46200)^{1,9}
\end{aligned}
$$

а в деформационной постановке

$$
\begin{aligned}
& \varepsilon_{P}\left(\sigma_{\mathrm{M} 1} ; n\right)=0,3884-0,3832(n / 72800)^{1,9} \\
& \varepsilon_{P}\left(\sigma_{\mathrm{M} 2} ; n\right)=0,3884-0,3815(n / 46200)^{1,9} .
\end{aligned}
$$


В приведенных выражениях $\sigma_{\mathrm{M} 1}=0,6 \sigma_{0,2}, \sigma_{\mathrm{m} 2}=0,8 \sigma_{0,2}$ и соответствующие долговечности $N_{1}=72800$ и $N_{2}=46200$ циклов. Использование кинетической кривой в расчетах элементов конструкций ограничено одноосным напряженным состоянием. Для построения теории циклической деградации нужны затратные эксперименты по вырождению предельной поверхности прочности материалов разных классов. Другой путь построения теории связан с принятием некоторой рабочей гипотезы, например о подобии исходной и вырожденной поверхностей пластичности или прочности и последующей экспериментальной проверке.

Метод ПДД представляется полезным и для исследования процессов деградации свойств материала при наводороживании в лабораторных условиях. Анализ процессов, сопровождающих взаимодействие металлических конструкций с водородом, позволяет выделить ряд определяющих параметров $[22,23]$. Кроме структуры и свойств самого материала влияние оказывают температура, давление, время, напряженное состояние детали, скорость деформации и др. В испытаниях образцов будет влиять и способ наводороживания, особенно при возможности фазовых переходов, вызываемых повышением температуры.

Решающее влияние на механические свойства сталей и сплавов оказывает такой трудно контролируемый параметр как концентрация водорода в металле. В лабораторных условиях средняя концентрация определяется взвешиванием на аналитических весах, использованием неэффективного механического средства изменения твердости и новых ядерно-физических методов [24]. В дальнейших испытаниях по построению кинетических зависимостей, аналогичных кривым циклической деградации, необходимо использовать современные способы наводороживания и измерения концентрации.

Диаграммы 3 и 4 на рис. 4 типичны для хрупких материалов, следовательно, наводороживание переводит пластичный титановый сплав в хрупкое состояние. Современные средства испытаний позволят построить и завершающий участок ПДД и оценить влияние водорода на сопротивление разрушению. Меняя условия режима наводороживания можно получить зависимости механических свойств от концентрации водорода, необходимые для введения в расчеты прочности и ресурса элементов реальных конструкций. Представляется, что в условиях многофакторного эксперимента использование компактных образцов, используемых при построении ПДД, будет целесообразным.

Роль испытаний с построением ПДД не ограничивается исследованием деградации при циклическом нагружении и наводороживании материала. Так изменение химического состава стали 20ГЛ привело к повышению прочности и располагаемой пластичности, но при этом снизилась трещиностойкость, определяемая углом наклона падающей ветви. Изделие из новой стали имело большую долговечность до появления усталостной трещины, но число циклов ее развития значительно сократилось, что оказалось недопустимым для литой детали [25]. Тем самым выявляется не только теоретическое, но и сугубо практическое значение использования ПДД при входном контроле механических свойств металла. Испытания с построением ПДД полезны также для исследования воздействия на свойства материала высоких и низких температур, импульсного нагружения образцов [26].

\section{Благодарность}

Авторы благодарны Т. И. Анисимовой за предоставление наводороженных титановых пластин для изготовления образцов.

Работа выполнена в рамках государственного задания, тема № 0391-2016-0001.

\section{4. Заключение}

Испытания малых тренированных образцов позволили установить физическую взаимосвязь статических и циклических свойств литых сталей. На этой базе строится феноменологическое описание усталостного процесса как перехода пластичного материала 
в хрупкое состояние. Дальнейшее уточнение полученных данных связано с определением степени локализации усталостных повреждений и учетом изменения модулей упругости и хрупкости.

Переход пластичного материала в хрупкое состояние зафиксирован и при действии водорода на титановый сплав. Продолжение испытаний с построением ПДД позволит оценить изменение его упругих, прочностных и пластических свойств, а также трещиностойкость при действии водорода.

Использование малого однократного образца в сочетании с жестким нагружающим устройством позволило преодолеть технические трудности в построении падающей ветви на машинной диаграмме в простых испытаниях. По изменению параметров ПДД тренированных образцов удается установить кинетику такого высоко локализованного процесса, как циклическая деградация материала. Описание процессов деградации исходных статических свойств конструкционных сталей и сплавов по результатам экспериментов с построением ПДД представляется весьма перспективным направлением построения физически обоснованных реологических уравнений материалов.

\section{Благодарность}

Работа выполнена в рамках государственного задания, тема № 0391-2016-0001.

\section{Литература}

1. Проников А. С. Надежность машин. - М. : Машиностроение, 1978. - 592 с.

2. Болотин В. В. Ресурс машин и конструкций. - М. : Машиностроение, 1990. - 448 с.

3. Veselov I., Emelyanov I., Fedotov V. Research of the Tension of the Shell Working in Hydrogen-Containing Environment // Proceedings of the 13th World Hydrogen Energy Conference, Beijing, China, June 12-15, 2000. - 2000. - P. 1041-1045.

4. Черданцев Ю. П. Методы исследования систем металл-водород : учеб. пособие. Томск : Изд-во ТПУ, 2008. - С. 286.

5. Рахматулин Х. А., Демьянов Ю. А. Прочность при интенсивных кратковременных нагрузках. - М. : Физматгиз, 1961. - 393 с.

6. Эволюция дислокационных субструктур при усталости / Н. А. Конева, О. В. Соснин, Л. А. Теплякова, В. Е. Громов, В. В. Коваленко. - Новокузнецк, 2001.

7. Терентьев В. Ф., Колмаков А. Г., Курганова Ю. А. Теория и практика повышения надежности и работоспособности конструкционных металлических материалов : учебное пособие. - Ульяновск : УлГТУ, 2010. - 268 с. ISBN 978-5-9795-0680-7.

8. Experimental functions of the resistance of alloy steel in tension and torsion / S. D. Volkov, Yu. P. Gus'kov, V. I. Krivospitskaya, V. I. Mironov, Y. P. Sokovnin, P. S. Sokolov // Strength of Materials. - 1979. - Vol. 11, iss. 1. - P. 1-5. - DOI: 10.1007/BF00806220.

9. Волков С. Д. Функция сопротивления материалов и постановка краевых задач механики разрушения. - Свердловск : УНЦ АН СССР, Ин-т металлургии, 1986. - 65 с.

10. Волков С. Д. Проблема прочности и механика разрушения // Проблемы прочности. 1978. - № 7. - С. 3-10.

11. Стружанов В. В., Миронов В. И. Деформационное разупрочнение материала в элементах конструкций. - Екатеринбург : Изд-во УрО РАН, 1995. - 190 с.

12. Mironov V. I., Lukashuk O. A. Influence of material structural inhomogeneity on fracture strength of constructional elements // J. Key Engineering Materials. - 2017. - Vol. 735. - P. 89-94. DOI: 10.4028/www.scientific.net/KEM.735.89.

13. Устройство и способ для испытания образцов материалов на растяжение: пат. 2251676 / Миронов В. И., Андронов В. А., Якушев А. В., Бамбулевич В. Б., ФГУП ПО «Уралвагонзавод». - № 2003130046/28 ; заявл. 09.10.2003 ; опубл. 10.05.2005, Бюл. № 13. 
14. Экспериментальные исследования свойств материалов при сложных термомеханических воздействиях / В. Э. Вильдеман, М. П. Третьяков, Т. В. Третьякова, Р. В. Бульбович, С. В. Словиков, А. В. Бабушкин, А. В. Ильиных, Д. С. Лобанов, А. В. Ипатова / под ред. В. Э. Вильдемана. - М. : Физматлит, 2012. - 204 с.

15. Lebedev A. A., Chausov N. G. Phenomenological fundamentals of the evaluation of crack resistance of materials on the basis of parameters of falling portions of strain diagrams // Strength of Materials. - 1983. - Vol. 15, iss. 2. - P. 155-160. - DOI: 10.1007/BF01523460.

16. Гольденблат И. И., Баженов В. Л., Копнов В. А. Длительная прочность в машиностроении. - М. : Машиностроение, 1977. - 248 с.

17. Работнов Ю. Н. Ползучесть элементов конструкций. - М. : Наука, 1955. - 752 с.

18. Карпенко Г. В., Крипяткевич Р. И. Влияние водорода на свойства стали. - М. : Металлургиздат, 1962. - 192 с.

19. Терентьев В. Ф. Усталостная прочность металлов и сплавов. - М. : Интермет Инжиниринг, 2002. -288 с.

20. Усталость и выносливость металлов : сб. статей / под ред. Г. В. Ужика. - М. : Изд-во иностр. лит., 1963. - 497 с.

21. Емельянов И. Г., Миронов В. И. Долговечность оболочечных конструкций. - Екатеринбург : РИО УрО РАН, 2012. - 217 с. - ISBN 978-5-7691-2322-1.

22. Овчинников И. И., Овчинников И. Г. Влияние водородосодержащей среды при высоких температурах и давлениях на поведение металлов и конструкций из них // Интернетжурнал «Науковедение». - № 4. - 2012. - URL: https://naukovedenie.ru/PDF/60tvn412.pdf (дата обращения: 20.09.2017).

23. Проницаемость водорода через металлы : учебное пособие / А. А. Писарев, И. В. Цветков, Е. Д. Маренков, С. С. Ярко. - М. : МИФИ, 2008. - 144 с.

24. Разработка экспресс-метода для контроля свойств вагонных сталей / В. И. Миронов, И. Г. Емельянов, А. В. Якушев, О. А. Лукашук // Транспорт Урала. - 2012. - № 2 (33). C. $13-18$.

25. Лебедев А. А., Чаусов Н. Г. Новые методы оценки деградации механических свойств металла конструкций в процессе наработки. - Киев : Изд-во ИПП НАНУ, 2004. 